\title{
Minimally Invasive Treatment for Back Pain
}

\author{
Hyunjin Jo, Jin-Sung Kim \\ Department of Neurosurgery, Seoul St. Mary's Hospital, The Catholic University of Korea, Seoul, Korea
}

Corresponding Author: Jin-Sung Kim, $\mathrm{MD}, \mathrm{PhD}$

Spine Center, Department of Neurosurgery, The Catholic Central Laboratory of Surgery (CCLS), Seoul St. Mary's Hospital, College of Medicine, The Catholic University of Korea, 222 Banpo-Daero, Seocho-gu, Seoul 06591, Korea

$$
\begin{aligned}
& \text { Tel: +82-2-2258-6128 } \\
& \text { Fax: +82-2-594-4248 } \\
& \text { E-mail: mddavidk@gmail.com, } \\
& \text { mdlukekim@gmail.com }
\end{aligned}
$$

Received: March 31, 2017

Revised: May 22, 2017

Accepted: May 24, 2017

\begin{abstract}
Low Back Pain (LBP) is considered as one of the most frequent disorders, which about $80 \%$ of adults experience in their lives. Chronic low back pain (CLBP) lasting 3 months or more has been also reported from $4 \%$ to $10 \%$. Although most people with back pain recover within a few months, back pain with chronic nature and frequently relapsed pattern is one of the important causes of job loss. Therefore, properly treating back pain has been a great issue to patients, their families, and spine surgeons. CLBP management consists of intervention strategies, physical therapy, surgery, and pharmacological treatment. The intervertebral disc (IVD), zygapophyseal (facet) joint and sacroiliac joint are the three primary structures that develop chronic low back pain. And Minimally Invasive Spinal Treatment (MIST) is being used increasingly for back pain. Since the late $20^{\text {th }}$ century, technological developments and advanced equipment (Radiofrequency, endoscopy, video, laser, etc) have also greatly contri- buted to the expansion of MIST for treatment of CLBP. We will review the literatures which dealed with diagnosis and treatment of CLBP and introduce newly proposed treatments.
\end{abstract}

Key Words: Chronic low back pain, Literature, Intervertebral disc, Zygapophyseal (facet) joint, Sacroiliac joint

\section{INTRODUCTION}

According to the literature, chronic low back pain (CLBP) is defined as low back pain lasting longer than 7-12 weeks ${ }^{20}$. It is reported that $70-85 \%$ of individuals have had back pain at some point in their lives ${ }^{2}$. Even though most people with back pain recover within a few months, chronic back pain with frequent relapsing is one of the important causes of job loss ${ }^{1)}$. CLBP is one of the most common causes of long-term disability, limiting movement, and influencing careers ${ }^{24,40)}$. Many patients have paid for this problem. In the United States, disability due to back pain has been estimated to cost approximately $\$ 28$ billion annually ${ }^{25,36)}$. Therefore, properly treating back pain has been a great issue to patients, their families, and spine surgeons. CLBP management consists of intervention strategies, physical therapy, surgery, and pharmacological treatment. The intervertebral disc (IVD), zygapophyseal (facet) joint and sacroiliac joint are the three primary structures that develop chronic low back pain. They are the most common causes of $\mathrm{CLBP}^{10,26)}$.

\section{Pathophysiology and Clinical Symptoms DISCOGENIC LOW BACK PAIN}

Degenerative damage to the intervertebral disk (IVD) plays a central role in the pathogenic mechanism leading to low back pain $^{6)}$. Recent studies have shown better understanding of the potential mechanisms that may cause CLBP. Many researchers found neovascularization and granulation tissue forming along annular tears ${ }^{31)}$. Several Growth factors (bFGF, TGF- $\beta$ ) were found in the region of a painful disk ${ }^{30)}$. The several cytokines (IL-6, $\mathrm{IL}-8$, and $\mathrm{PGE}_{2}$ ) are released from the granulation tissue and may sensitize the nociceptors ${ }^{39}$. Neo-innervation and nociceptor sensitization may lead to discogenic pain.

\section{Characteristics of discogenic low back pain}

1. Sitting intolerance

2. Frequent back pain attacks after physical work or exercise

3. Frequently needing to stand or difficulty standing (extension catch)

4. Difficulty in maintaining body position

5. Inability to lift heavy materials

\section{FACETAL PAIN}

Lumbar facet arthropathy is an important source of low back pain ${ }^{177}$. Goldthwait in 1911 first stated that "the peculiarities of the facet joints" were responsible for CLBP and instability. In 1933, Ghormleyz first described the "facet syndrome," ${ }^{, 14}$. Facet joints have synovial linings and capsules. They are highly in- 
nervated since some have free nerve endings ${ }^{27)}$ (Fig. 1). Facet joints become inflamed and can progress to joint degeneration. Facet pain is aggravated by patient motion including extension and rotation, or is associated with lumbar rigidity. Clinical symptoms and imaging studies suggest no other obvious cause of the back pain.

\section{SACROILIAC JOINT PAIN}

The sacroiliac joint is a source of pain in the lower back and buttocks in approximately 15\% of the population. Diagnosis of sacroiliac joint-mediated pain is difficult because the symptoms are similar to other causes of back pain. Most sacroiliac joint pain is localized around the posterior superior iliac spine. Magnetic resonance imaging, computed tomography, and bone scans of the sacroiliac joint cannot reliably determine whether the joint is the source of the pain. Controlled analgesic injections of the sacroiliac joint are the most important tool in the diagnosis.

\section{Clinical Symptoms \& Physical Examinations - Few Patho- gnomonic Tests for SIJ Pain}

1. Thigh thrust/Femoral shear/Posterior shear

2. Gillet's test for aberrant sacroiliac motion

3. Gaenslen's (Pelvic torsion) test

4. Sacral thrust (Tenderness over the ipsilateral sacroiliac joint)

5. The Fortin finger test

6. Distraction (Gapping) test

7. Compression (Approximation) test

8. Patrick's (Faber's) test

\section{Sacroiliac Joint}

1. Thick 6-mm sacral cartilage and thin 1-mm iliac cartilage.

2. Synovial, fluid-filled diarthrodial joint enveloped by a fibrous

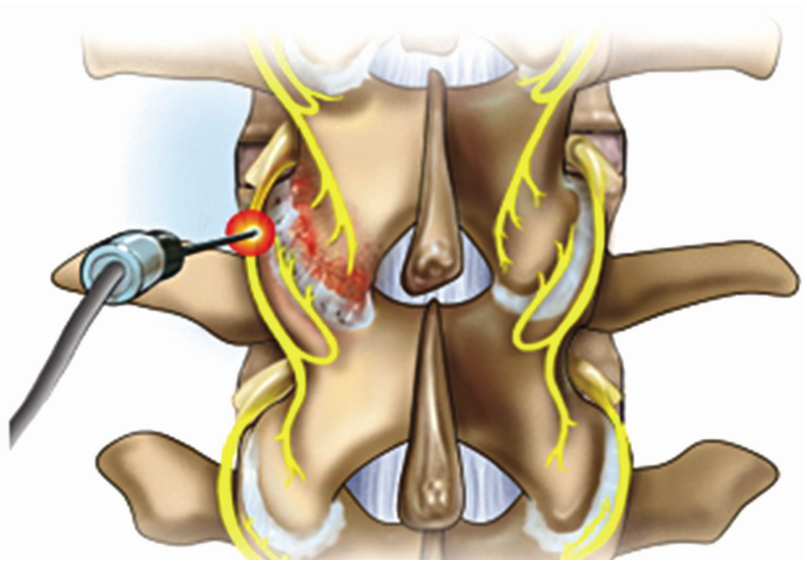

Fig. 1. The facet joint is innervated by the medial branch of the dorsal ramus at its own level and to the level below. When the RF rhizotomy is done, denervation target is the medial branch crossing the proximal transverse process. capsule between the sacrum and ilia ${ }^{12,38)}$.

3. Many ligaments around SIJ contribute to anatomical stability ${ }^{34)}$.

\section{Innervation}

1. The joint is innervated anteriorly by the L5-S2 ventral rami and the sacral plexus, and posteriorly by lateral branches from the S1-S4 dorsal rami $^{7 \text { ). }}$.

2. Predominant innervation from the $\mathrm{S} 1$ dorsal ramus, with additional innervation from the S2-S4 dorsal rami but not from the ventral sacral plexus ${ }^{13,16)}$.

\section{Treatment}

Currently, there are no universally accepted guidelines for managing CLBP, and treatment seems to be governed mainly by tradition and personal experience ${ }^{37)}$. The treatment modalities can be classified into four major stepwise categories: conservative (pharmacological and physiotherapy), rehabilitation and exercise programs, interventional treatments, and surgical procedures. A stepwise approach to CLBP may be effective to reduce the economic burden with proper use of the less invasive treatments. Interventional pain management or surgical techniques should be only considered when conservative treatment fails to provide successful pain control and improve quality of life. Moreover, in the present era of evidence based medicine, this kind of stepwise approach to CLBP is strongly recommended for achieve successful outcomes with the best available level of evidence.

\section{Minimally Invasive (Interventional) Treatment for Back Pain}

\section{DISCOGENIC BACK PAIN}

\section{1) Intradiscal Thermal Lesioning}

This procedure was demonstrated by Sluijter \& Van Kleefdirect RF heating of the disc ${ }^{35)}$. However, percutaneous intradiscal radiofrequency thermocoagulation (90 seconds, $70 \mathrm{C}$ ) is not effective in reducing chronic discogenic low back pain ${ }^{5}$. Although the mechanism of pain relief using heating for discogenic back pain is unclear, two hypotheses are usually suggested. The first is denervation of the disc tissue or destruction of the overgrowth of nociceptors. The second is changing and remodeling the structure of the collagen fibers in the annulus, causing an increase in annular stability. However, histological studies involving Intradiscal Electrothermal Therapy (IDET) did not support these two hypotheses ${ }^{33)}$.

\section{2) IDET}

The role of intradiscal electrothermal therapy (IDET) in the 
treatment of discogenic back pain remains controversial. Freeman et al, in a randomized, double-blind, controlled trial, showed no difference between the group undergoing IDET and the group undergoing the sham procedure, with no improvement in either group ${ }^{21)}$. The use of IDET in the treatment of discogenic back pain remains controversial, and without good, long-term results, a recommendation for its use cannot be given.

\section{3) Disc-FX (Elliquence-Oceanside, NY) (Fig. 2)}

Some investigators suggest that most common cause of IDET failure may be due to incorrect target lesioning because most pain generators in discogenic pain are located in interposed disc tissue in the posterior annulus. The duration of clinical success is dependent on the thickness of the annulus after thermal modulation. The flexible RF Elliquence probe could ablate ingrown granulation tissue and nerve endings already in the posterior annular defects, and shrink the annular openings ${ }^{21)}$.

\section{4) Laser Annuloplasty}

Percutaneous endoscopic laser annuloplasty (PELA), a minimally invasive technique, uses LASE (Laser-assisted spinal endoscopy) to directly shrink and coagulate the interposed disc tissue in the posterior annulus associated with annular tears ${ }^{28)}$.

\section{Mechanism}

1. Targeted removal of granulation tissues in the posterior annulus

2. Laser during PELA blocks the sensory nerve surrounding the annulus

3. Continuous saline irrigation removes chemical irritants

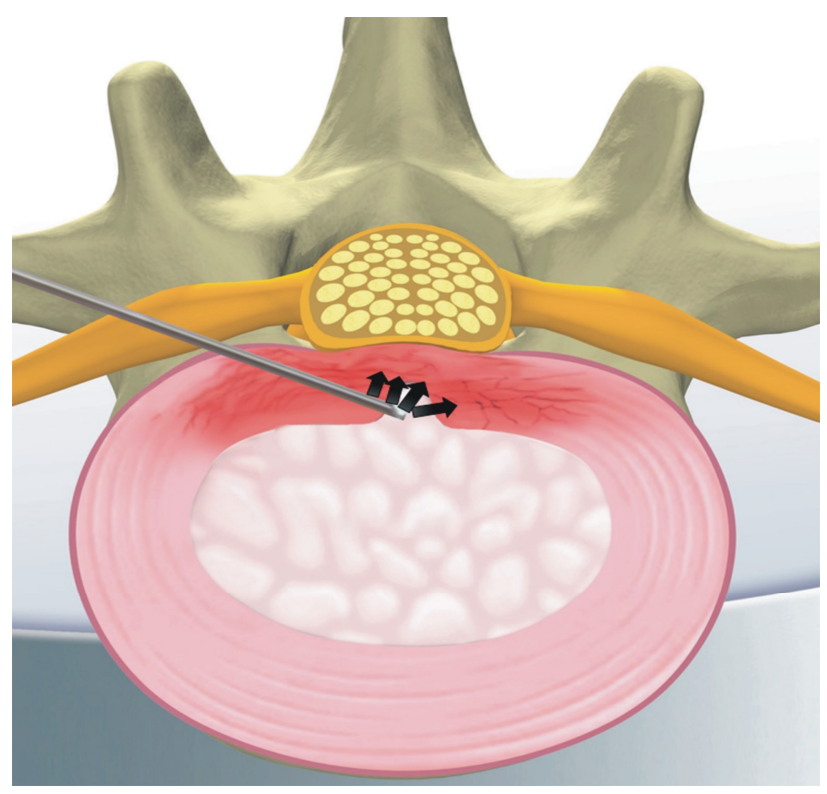

Fig. 2. Illustration of Disc-FX.

\section{5) Percutaneous Disc Decompression Device (L'DISQ)} $(\text { Fig. 3) })^{22}$

The disadvantage of the Nucleoplasty device, and indeed the disadvantage of most other minimally invasive devices and techniques, is the inability to easily reach the herniated nucleus. However, In contrast to the Nucleoplasty device, the L'DISO (U\&I Co., Uijeongbu, Korea) wand has a navigable tip that can be curved by rotating a control wheel and directed into a disc herniation.
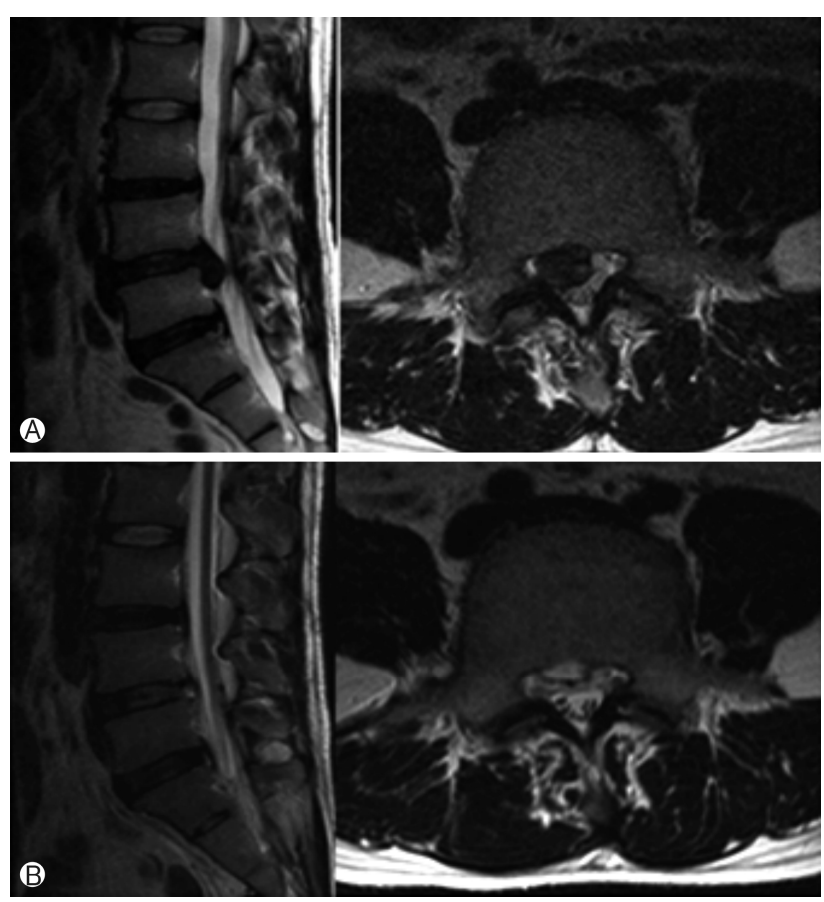

Fig. 4. Preoperative sagittal (left) and axial images (right) show huge down-migrated lumbar disc herniation (A). ANPostoperative sagittal (left) and axial images (right) show complete removal of herniated disc fragments (B).

Compared with an open surgical discectomy, percutaneous removal through a relatively small bore introducer cannula placed directly into the herniation or through the posterior lateral annu-

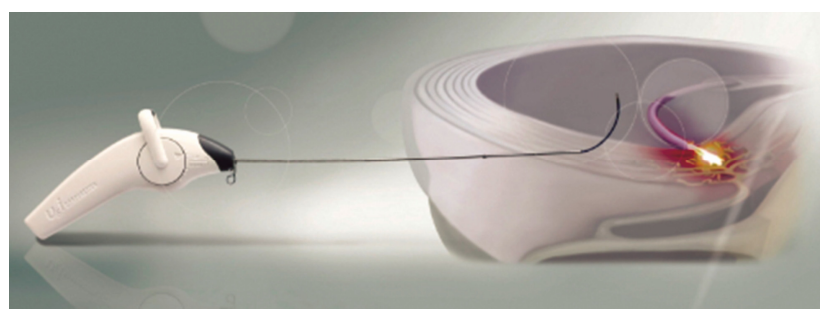

Fig. 3. The wand and navigable tip of the L'DISO is illustrated. The tip of the wand is curved to the desired angle by rotating the control wheel. After placing the tip into the posterior annulus, plasma energy induced by radiofrequency is used to ablate and decompress the disc herniation. 
lus will theoretically better preserve the integrity of the outer annulus and potentially reduce the $7 \%$ to $25 \%$ reherniation rate following open discectomy.

Theoretically, Because the distance between the two electrodes on the L'DISO tip is $2 \mathrm{~mm}$, a nerve root that is greater than $2 \mathrm{~mm}$ from the tip is safe from electric injury.

\section{6) PELDA (Percutaneous Endoscopic Lumbar Discectomy and Annuloplasty) (Fig. 4)}

In the IDET procedure, the relatively high failure rate may be due to blind thermo-coagulation and indirect decompression. In contrast, PELDA directly achieved the removal of the compressing extradural fragment and anchoring disc fragment in the annular fissure. It could achieve (1) decompression through the removal of the disc fragment and reduction of the intradiscal pressure; and (2) thermal ablation with RF and laser, which repaired the annular defect of neoinnervation and neovascularization. However, to validate the clinically successful results, a well designed randomized controlled trial should be considered.

\section{7) Percutaneous Adhesiolysis}

Percutaneous lysis of adhesions (also known as decompressive epidural adhesiolysis) is a procedure developed by Dr. Gabor Racz in 1989 for the patients with CLBP who have failed to respond to conservative treatments. The purpose of this interventional procedure is to break down fibrous adhesion scar tissues in the epidural space and deliver proper medication (i.e. local anesthetics and corticosteroids) (Fig. 5). However, it remains a debate that adhesion scars in the epidural space cause CLBP. Fibrous epidural scars can develop after surgical laminectomy, or can occur secondary to an annular tear, hematoma or infection. The adhesion scars can limit free movement of neurovascular bundles in the intervertebral foramen and the central spinal canal. Using epidural adhesiolysis, it is possible to deliver medications to targeted structures directly.
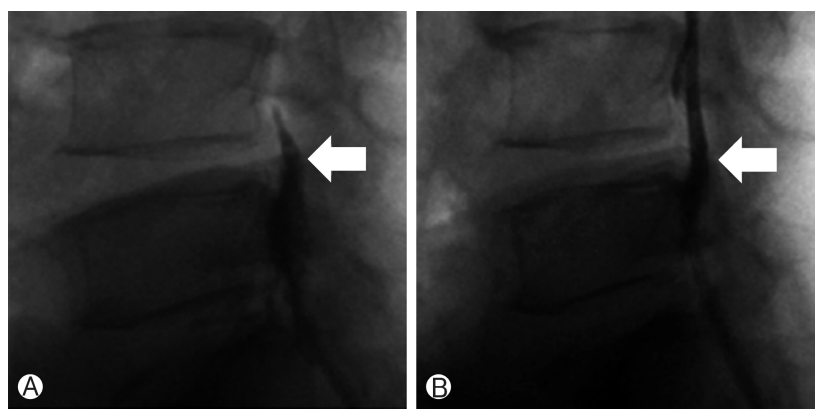

Fig. 7. (A) Epidurogram before trans-sacral epiduroscopic laser decompression (SELD) showing the outline of herniation and flow obstruction caused by the herniated nucleus pulposus and adhesion at the pathologic level. (B) Epidurogram after SELD showing a flattened outline of herniation and free flow at the previous pathologic level.

\section{8) Trans-Sacral Epiduroscopic Laser Decompression $\left(\right.$ SELD) ${ }^{29)}$}

\section{Introduction}

In recent years, remarkable progress has been made in the area of epiduroscopic treatment of spinal lesions using a laser as a less invasive surgical alternative to traditional open surgery. Epiduroscopy accesses through the sacral hiatus, to permit direct visualization of lumbar epidural lesions. This steerable flexible epiduroscopic laser system is used to confirm epidural pathologic findings and provide precise and directed therapy at the same time. Recently, trans-sacral epiduroscopic laser decompression (SELD) has been performed by many surgeons for discogenic low back pain or herniated disc lesion.

In this procedure, a steerable flexible epiduroscopic laser system is used to confirm epidural pathologic findings and provide precise and directed therapy at the same time.

Epiduroscopy accesses through the body's natural opening, namely the sacral hiatus.

\section{Technique}

The procedure was performed with the patient under local anesthesia. A $5 \mathrm{~mm}$ skin incision was made over the sacral hiatus. The sacrococcygeal ligament was punctured with a Tuohy needle under fluoroscopic guidance followed by a guide wire and dilator. Subsequently, a $3.0 \mathrm{~mm}$ steerable VGC was introduced. Through the VGC, epiduroscope and the Ho: YAG laser were advanced into the end of the catheter to visualize the epidural space and perform HNP ablation. After introducing the VGC, fluoroscopy, and epiduroscopy were used to confirm that the tip of the catheter was located at the most inferior part of the targeted disc, covering the PLL (Fig. 6A). Radio-opaque dye was injected to obtain an epidurogram, showing the outline of herniation and flow obstruction caused by HNP and adhesion at the pathologic level (Fig. 7A). Under direct vision with epiduroscopy, adhesiolysis and the size of the herniated disc, which
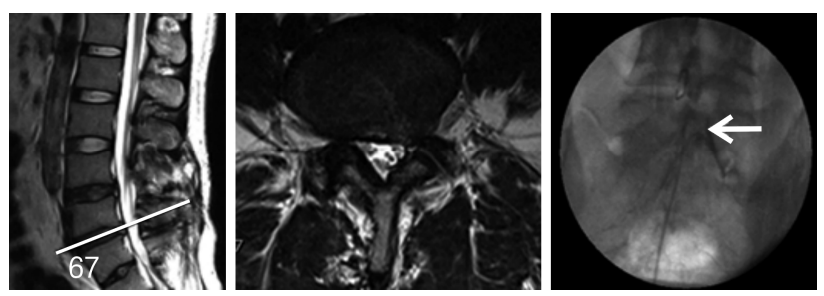

Fig. 5. 36-year old male underwent two lumbar operations at the L4-5 and L5S1 level. He suffered from back and radicular leg pain along the S1 dermatome. MRI revealed no definite neural entrapment. Sagittal \& axial MRI images show black disc and postoperative changes of laminectomy at $L 45$ and L5S1 level. Percutaneous adhesiolysis was done and fluoroscopic image shows the tip of a catheter located in lateral recess and well traced S1 nerve root. 
was located below the PLL, were reduced by the Ho: YAG laser (Fig. 6B, C). The floating and sequestrated HNP was removed using $1 \mathrm{~mm}$ forceps (Fig. 6D). Repeat epidurogram should show a flattened outline of herniation and free flow at the previous pathologic level (Fig. 7B).

\section{Result}

SELD showed rapid improvement of back pain and radiculopathy with significant differences in the VAS and ODI scores between preoperative and postoperative data. There were no significant complications affecting the clinical outcomes, such as nerve damage caused by thermal injury, infection, or postoperative hematoma

\section{9) Transforaminal epiduroscopic laser annuloplasty (TELA)}

This procedure has many similarities in basic function with SELD. However, each has a totally different designated target in, and different access to, the epidural space of the lumbar spine. The target and access are the posterior part of the annulus and the intervertebral foramen respectively.

TELA is a similar technique to the outside-in technique of percutaneous endoscopic lumbar discectomy (PELD). However, this procedure has a different entry point with PELD. The usual skin entry point is less than $12 \mathrm{~cm}$ off the midline so a curved
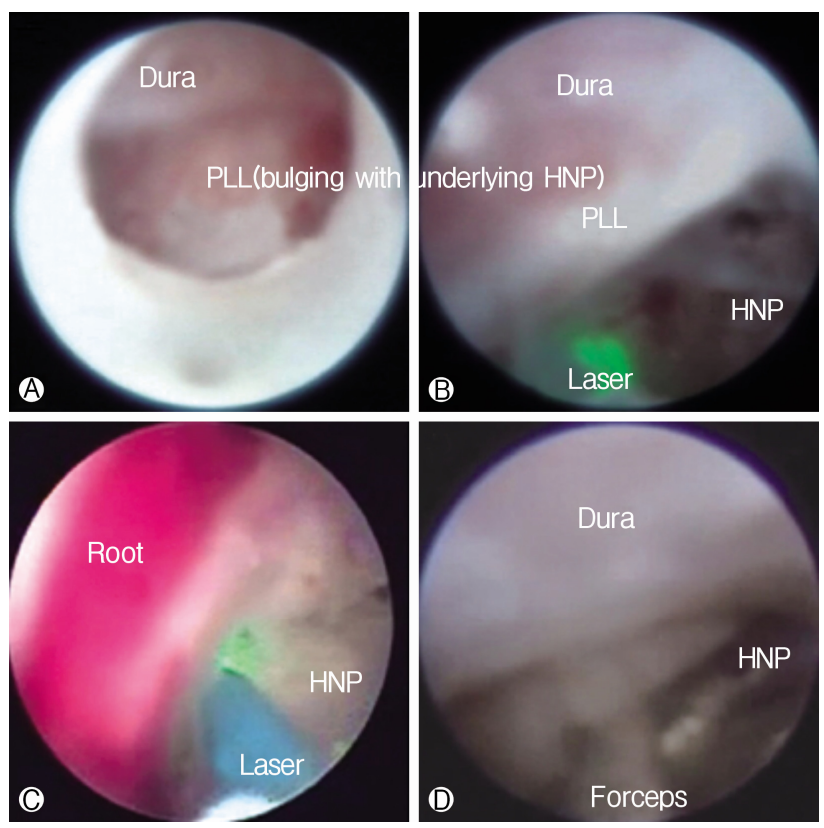

Fig. 6. Epiduroscopic view. (A) The dura is compressed by the bulging posterior longitudinal ligament (PLL) with an underlying herniated nucleus pulposus (HNP). (B) and (C) The ruptured HNP below the PLL is decompressed by the Ho:YAG laser (VersaPulse P20; Lumenis, Yokneam, Israel). (D) The ruptured HNP is remoed using $1 \mathrm{~mm}$ forceps. scope can be used (Fig. 8).

\section{FACETAL BACK PAIN}

In the facet joint pain, there are two treatment modalities available: medial branch blocks and radiofrequency neurotomy.

\section{Interventional Treatment}

\section{i. Conventional RF rhizotomy (Fig. 9)}

Many clinical trials suggest that radiofrequency denervation of lumbar facet joints provides significant pain relief. The success rate is about $50 \%$ to $70 \%$. Moreover, its clinical improvement usually lasts a few months. Some patients experience recurrence of pain as the medial branch of dorsal ramus regrows. In patients who have a recurrence of back pain, repeated procedures are needed.

ii. Endoscopic dorsal ramus rhizotomy (Fig. 10)

\section{Procedure}

The procedure was performed with the patient under local anesthesia. The target point is the junction of the transverse process with the base of the superior articular process (SAP). First, an $18 \mathrm{G}$ needle is docked onto target point. Then the K-wire, obturator, and beveled working cannula are serially inserted. After checking the proper location of the cannula, forceps are used to remove fatty tissue between muscles. The RF probe is inserted through the endoscope. Then, soft tissue is removed at the base of the transverse process, including medial and lateral branches.

\section{Clinical outcomes ${ }^{41)}$}

Yeung et al. reported the clinical success rate is more than $90 \%$, and lasts more than 1 or 2 years. No patients got worse after this procedure. They also suggest that

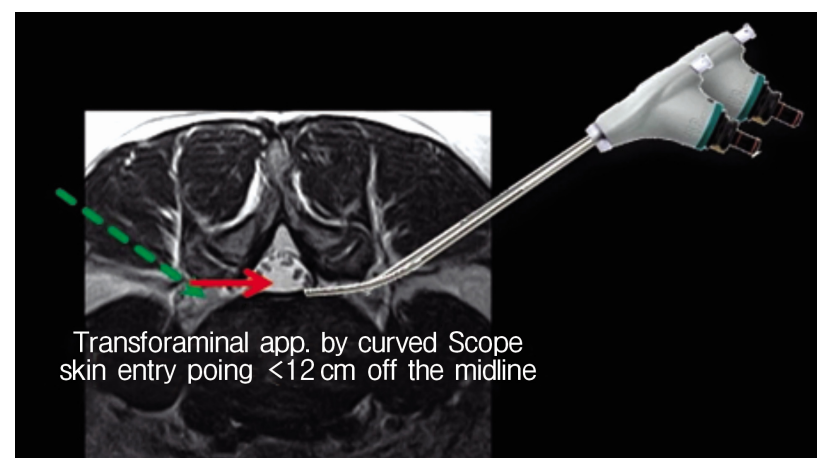

Fig. 8. The usual skin entry point is more medial point compared to conventional percutaneous transforaminal procedure due to the curved endoscope. 
endoscopic dorsal ramus rhizotomy helps surgeons to get more aggressive ablation than conventional RF rhizotomy, which improves results and delays recurrence of pain.

\section{SACROILIAC JOINT PAIN}

Most patients who suffer from CLBP usually have not only discogenic, but also facetal or SIJ pain. It is estimated that $15 \%-25 \%$ of individuals who present with CLBP actually had pain from SIJ. Once the diagnosis of SIJ pain is proven, there are three modalities of treatments available. These include intraarticular injections, medial branch blocks, and radiofrequency (conventional and cooled) neurotomy: C-arm guided and endoscopic guided ${ }^{3,4,8,19)}$.

Recently, SIJ fusion is carefully recommended to patients who suffered from pain in spite of interventional pain managements such as blocks or radiofrequency neurotomy $y^{9,32)}$.

\section{Treatment of SIJ Pain}

1. conservative treatment

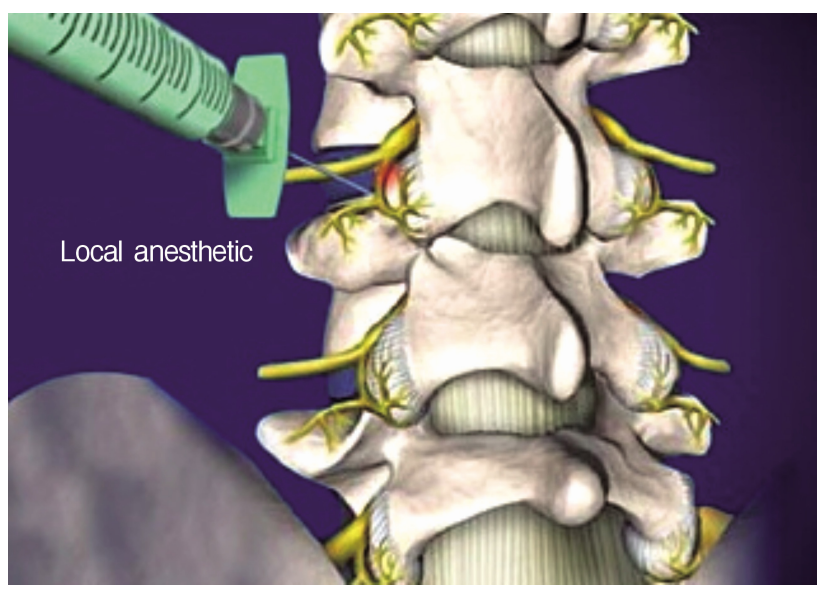

Fig. 9. The target of RF rhizotomy is the junction of the transverse process with the base of the superior articular process (SAP).
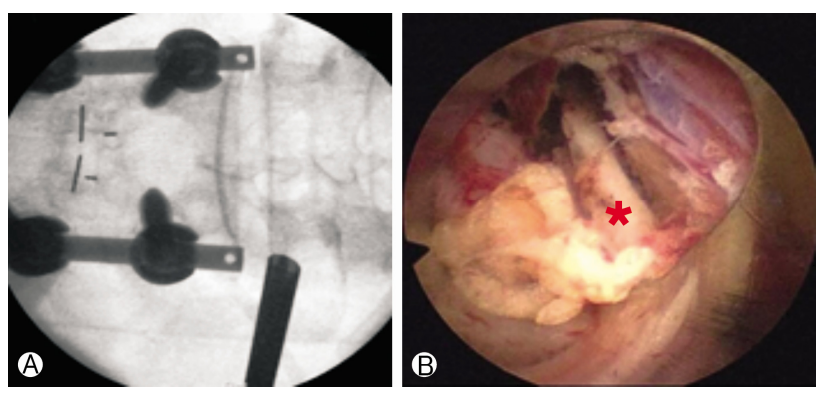

Fig. 10. Fluoroscopic view (A) of endoscopic working cannula and endoscopic view (B) showing the medial branch of dorsal ramus (red star).
A. rehabilitation

B. physical therapy

2. Pharmacologic therapy

3. Intra-articular steroid injections (Fig. 11)

4. RF denervation

\section{Endoscopic Radiofrequency Ablation of the Sacroiliac Joint Complex ${ }^{8)}$}

\section{Introduction}

Intra-articular injection of the joint using a mixture of steroids and local anesthetics is a simple procedure and provides quick pain relief, but the effect is short-lived ${ }^{23)}$. In addition, SIJ fusion is an invasive surgical procedure that should be reserved for cases refractory to non-operative measures ${ }^{11,15)}$. On the other hand, radiofrequency ablation (RFA) of the SIJ complex offers longer lasting

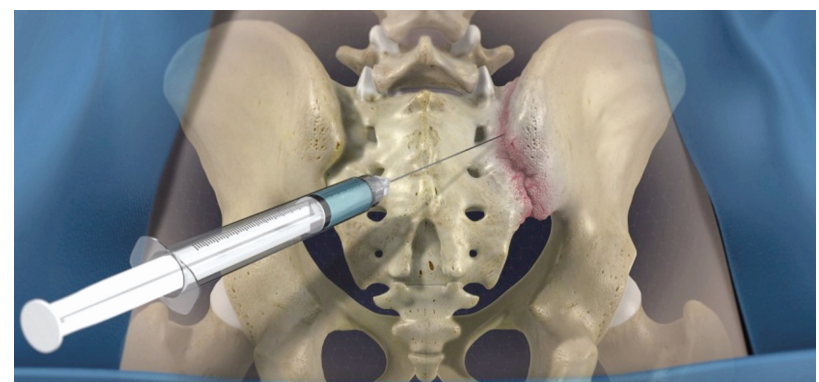

Fig. 11. Shows the intraarticular steroid injection to SIJ.
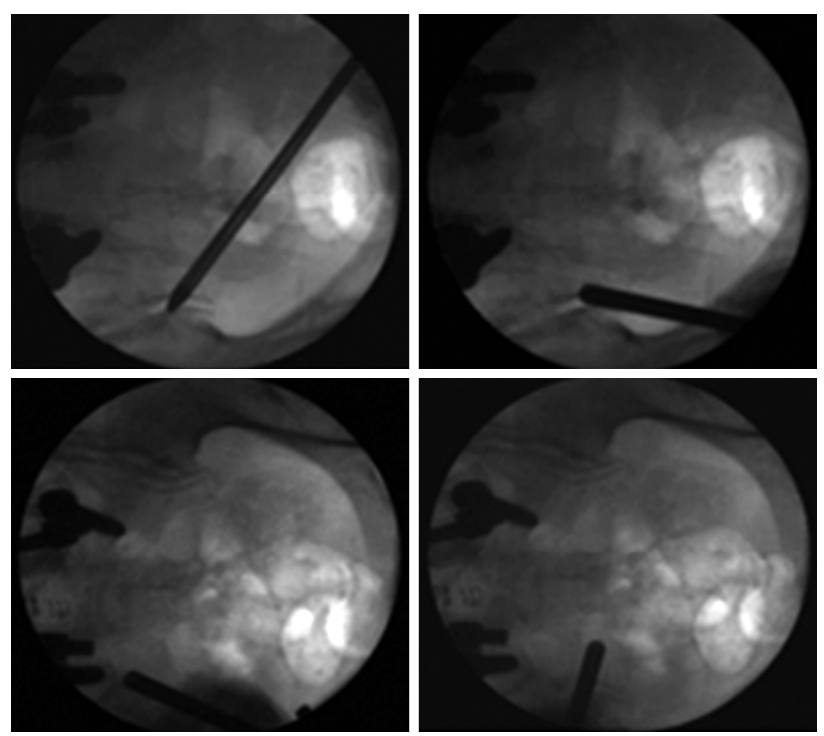

Fig. 12. Fluoroscopic view of the endoscopic cannula tip in various positions during the procedure. The cannula tip can be moved in the subcutaneous plane and can be repositioned without causing much discomfort. If patients did experience discomfort, an additional lidocaine injection was applied. 

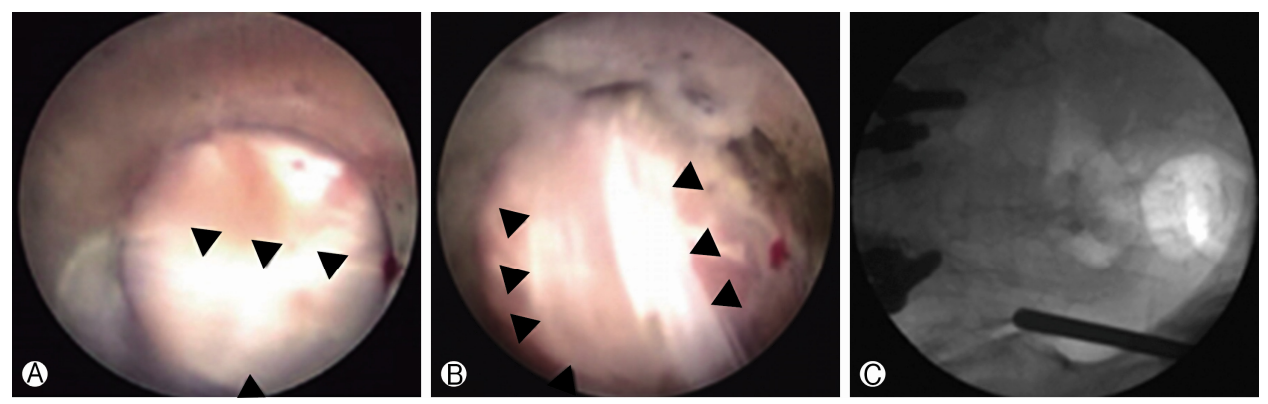

Fig. 13. (A) and (B). Long posterior ligament (black arrowheads) overlying the posterior capsule of the SIJ. (C) Corresponding position of the cannula tip in the anteroposterior fluoroscopic image.

effects and has gained wide attention in the last decade ${ }^{18)}$, with increasing numbers of reports advocating for its efficacy $^{23)}$. The target structures are the lateral branches of the sacral rami, the dorsal ramus of $L 5$, and the ligamentous structures overlying the joint. However, variations in the pattern of innervation exist between individuals, which provides a challenge for surgeons. Due to these variations, Endoscopic radiofrequency ablation has been utilized in the treatment of facetogenic CLBP. Choi et al. reported the efficacy of this technique when applied to SIJ-associated CLBP ${ }^{8)}$.

\section{Techniques}

All patients were placed in the prone position on chest rolls on a radiolucent table. Fluoroscopy guided obturator docked on the posterior SIJ. Under endoscopic visualization, the posterior sacroiliac ligament and its overlying soft tissue were ablated using a Trigger-Flex bipolar probe (Elman International, Inc.) that was introduced through the working channel of the endoscope. First, ablation was done to the perforating branches that innervate the posterior capsule of the SIJ. After visual confirmation of the long posterior sacroiliac ligament (Fig. 15), the fluoroscope was then adjusted to obtain an anterior-posterior view. Next, using the wanding maneuver of the cannula, the cannula tip was moved along the subcutaneous plane toward the region lateral to the S1-S3 sacral foramina, and a linear multi-depth lesion was made along the line connecting the lateral margins of the S1-3 sacral foramina (Fig. 16). Continuous saline irrigation was maintained throughout the procedure to minimize thermal injury to the surrounding structures. After ablation of the target points, the endoscope and cannula were removed. One-point suture with Nylon was used, and a sterile dressing was applied.

5. Surgical treatments - SIJ fusion

1) Anterior approach

A. Anterior ilioinguinal approach

B. Underneath/deep to iliacus
C. Limitation - retraction of $L 5$ nerve root medially 2) Smith Petersen Approach

A. Elevate gluteus musculature

B. Limitation - cluneal nerves posteriorly, sciatic notch with superior gluteal neurovascular bundle

3) Transiliac approach

A. Mini-open muscle splitting

B. Limitation - anterior common iliac, external iliac vessels, L5 nerve root, lumbosacral plexus, posteriorly S1, S2 neural canals.

4) Posterior approach

A. Midline either muscle splitting Wiltse, or midline muscle elevating

B. Limitations - posterior ligamentous structures

\section{REFERENCES}

1. : Prevalence of disabilities and associated health conditions among adults--United States, 1999. MMWR Morb Mortal Wkly Rep 50:120-125, 2001

2. Andersson GB: Epidemiological features of chronic low-back pain. Lancet 354:581-585, 1999

3. Ashman B, Norvell DC, Hermsmeyer JT: Chronic sacroiliac joint pain: fusion versus denervation as treatment options. Evidencebased Spine-care Journal 1:35-44, 2010

4. Aydin SM, Gharibo CG, Mehnert M, Stitik TP: The role of radiofrequency ablation for sacroiliac joint pain: a meta-analysis. PM\&R 2:842-851, 2010

5. Barendse GA, van den Berg SG, Kessels AH, Weber WE, van Kleef M: Randomized controlled trial of percutaneous intradiscal radiofrequency thermocoagulation for chronic discogenic back pain: lack of effect from a 90-second $70 \mathrm{C}$ lesion. Spine 26:287-292, 2001

6. Benneker LM, Heini PF, Alini M, Anderson SE, Ito K: 2004 Young Investigator Award Winner: vertebral endplate marrow contact channel occlusions and intervertebral disc degeneration. Spine (Phila Pa 1976) 30:167-173, 2005

7. Buchowski JM, Kebaish KM, Sinkov V, Cohen DB, Sieber AN, Kostuik JP: Functional and radiographic outcome of sacroiliac arthrodesis for the disorders of the sacroiliac joint. The Spine Journal 5:520-528, 2005

8. Choi W-S, Kim J-S, Ryu K-S, Hur J-W, Seong J-H, Cho H-J: 
Endoscopic Radiofrequency Ablation of the Sacroiliac Joint Complex in the Treatment of Chronic Low Back Pain: A Preliminary Study of Feasibility and Efficacy of a Novel Technique. BioMed Research International 2016, 2016

9. Cohen SP, Chen Y, Neufeld NJ: Sacroiliac joint pain: a comprehensive review of epidemiology, diagnosis and treatment. Expert Review of Neurotherapeutics 13:99-116, 2013

10. Datta S, Lee M, Falco FJ, Bryce DA, Hayek SM: Systematic assessment of diagnostic accuracy and therapeutic utility of lumbar facet joint interventions. Pain Physician 12:437-460, 2009

11. Fortin J: The anatomy of the lateral branches of the sacral dorsal rami: implications for radiofrequency ablation. Pain Physician 17:459-464, 2014

12. Fortin JD: Sacroiliac Joint Dysfunction. Journal of Back and Musculoskeletal Rehabilitation 3:31-43, 1993

13. Fortin JD: Saoroiliao Joint Innervation and Pain. 1999

14. Ghormley RK: Low back pain: with special reference to the articular facets, with presentation of an operative procedure. Journal of the American Medical Association 101:1773-1777, 1933

15. Giannikas K, Khan A, Karski M, Maxwell H: Sacroiliac joint fusion for chronic pain: a simple technique avoiding the use of metalwork. European Spine Journal 13:253-256, 2004

16. Grob K, Neuhuber W, Kissling R: Innervation of the sacroiliac joint of the human. Zeitschrift fur Rheumatologie 54:117-122, 1994

17. Helbig T, Lee CK: The lumbar facet syndrome. Spine (Phila Pa 1976) 13:61-64, 1988

18. Ikeda R: Innervation of the sacroiliac joint. Macroscopical and histological studies. Nihon Ika Daigaku Zasshi 58:587-596, 1991

19. Karaman H, Kavak GÖ, Tüfek A, Çelik F, Yıldırım ZB, Akdemir MS, et al: Cooled radiofrequency application for treatment of sacroiliac joint pain. Acta Neurochirurgica 153:1461-1468, 2011

20. Karimi N, Akbarov P, Rahnama L: Effects of segmental traction therapy on lumbar disc herniation in patients with acute low back pain measured by magnetic resonance imaging: A single arm clinical trial. J Back Musculoskelet Rehabil 30:247-253, 2017

21. Kumar N, Kumar A, Shah Siddharth M, Shah Sambhav P, Tan $\mathrm{J}$ : Annulo-nucleoplasty using Disc-FX in the management of lumbar disc pathology: Early results. International Journal of Spine Surgery 8, 2014

22. Lee SH, Derby R, Kim GH, Kang S, Kim NH, Yoo SH, et al: Efficacy of a new navigable percutaneous disc decompression device (L'DISQ) in patients with herniated nucleus pulposus related to radicular pain. Pain Medicine 12:370-376, 2011

23. Lee SH, Lee S-H, Lim KT: Trans-Sacral epiduroscopic laser decompression for symptomatic lumbar disc herniation: A preliminary case series. Photomedicine and Laser Surgery 34:121129, 2016

24. Liddle SD, Baxter GD, Gracey JH: Exercise and chronic low back pain: what works? Pain 107:176-190, 2004

25. Maetzel A, Li L: The economic burden of low back pain: a review of studies published between 1996 and 2001. Best Pract Res Clin Rheumatol 16:23-30, 2002

26. Manchikanti L, Boswell MV, Singh V, Benyamin RM, Fellows B, Abdi S, et al: Comprehensive evidence-based guidelines for interventional techniques in the management of chronic spinal pain. Pain Physician 12:699-802, 2009

27. McLain RF, Pickar JG: Mechanoreceptor endings in human thoracic and lumbar facet joints. Spine 23:168-173, 1998

28. Niagara W, Spine A: Automated percutaneous lumbar discectomy for the contained herniated lumbar disc: A systematic assessment of evidence. Pain Physician 12:601-620, 2009

29. Patel N, Gross A, Brown L, Gekht G: A randomized, placebocontrolled study to assess the efficacy of lateral branch neurotomy for chronic sacroiliac joint pain. Pain Medicine 13:383398, 2012

30. Peng B, Hao J, Hou S, Wu W, Jiang D, Fu X, et al: Possible pathogenesis of painful intervertebral disc degeneration. Spine (Phila Pa 1976) 31:560-566, 2006

31. Peng B, Wu W, Hou S, Li P, Zhang C, Yang Y: The pathogenesis of discogenic low back pain. J Bone Joint Surg Br 87:62-67, 2005

32. Phillips FM, Garfin SR: Minimally invasive sacroiliac joint fusion. Orthopedics 34:600-601, 2011

33. Shah RV, Lutz GE, Lee J, Doty SB, Rodeo S: Intradiskal electrothermal therapy: a preliminary histologic study. Archives of Physical Medicine and Rehabilitation 82:1230-1237, 2001

34. Slipman CW, Whyte W, Chow DW, Chou L, Lenrow D, Ellen M: Sacroiliac joint syndrome. Pain Physician 4:143-152, 2001

35. Sluijter ME, van Kleef M, Barendse GA, Weber W: Letters. Spine 23:745, 1998

36. Spivak JM: Vertebroplasty: weighing the benefits and the risks. Am Fam Physician 66:565, 2002

37. Varrassi G, Muller-Schwefe G, Pergolizzi J, Oronska A, Morlion B, Mavrocordatos P, et al: Pharmacological treatment of chronic pain - the need for CHANGE. Curr Med Res Opin 26:12311245,2010

38. Vleeming A, Volkers A, Snijders C, Stoeckart R: Relation Between Form and Function in the Sacroiliac Joint: Part II: Biomechanical Aspects. Spine 15:133-136, 1990

39. Weiler C, Nerlich AG, Bachmeier BE, Boos N: Expression and distribution of tumor necrosis factor alpha in human lumbar intervertebral discs: a study in surgical specimen and autopsy controls. Spine (Phila Pa 1976) 30:44-53; discussion 54, 2005

40. Wenig CM, Schmidt CO, Kohlmann T, Schweikert B: Costs of back pain in Germany. Eur J Pain 13:280-286, 2009

41. Yeung A, Gore S: Endoscopically guided foraminal and dorsal rhizotomy for chronic axial back pain based on cadaver and endoscopically visualized anatomic study. Int J Spine Surg 8, 2014 